\title{
REVIEW ON MATERIAL HANDLING SYSTEM USING PLC CONTROL FOR SUGAR TRANSPORTATION
}

\author{
Rupa Sharma 1 , Vrushabh Rakhade ${ }^{2}$, Shraddha Akolkar ${ }^{3}$, Yamini Tupe ${ }^{4}$, Nilesh Thite ${ }^{5}$, Ashish Pawar \\ ${ }^{I}$ Department of Mechanical Engineering, Anantrao Pawar college of engineering \& Research, Parvati Pune-09, \\ Savitribai Phule Pune University, India \\ ${ }^{2}$ Department of Mechanical Engineering, Anantrao Pawar college of engineering \& Research, Parvati Pune-09, \\ Savitribai Phule Pune University, India \\ ${ }^{3}$ Department of Mechanical Engineering, Anantrao Pawar college of engineering \& Research, Parvati Pune-09, \\ Savitribai Phule Pune University, India \\ ${ }^{4}$ Department of Mechanical Engineering, Anantrao Pawar college of engineering \& Research, Parvati Pune-09, \\ Savitribai Phule Pune University, India \\ ${ }^{5}$ Department of Mechanical Engineering, Anantrao Pawar college of engineering \& Research, Parvati Pune-09, \\ Savitribai Phule Pune University, India \\ ${ }^{6}$ Professor, Department of Mechanical Engineering, Anantrao Pawar college of engineering \& Research, Parvati \\ Pune-09, Savitribai Phule Pune University, India
}

\begin{abstract}
This paper represents design parameters for Belt conveyor system. It is used particularly in sugar industry as well as in any powder industry. This system consists of hopper, screw feeder, belt conveyor, metal detector and check weigher. The design parameters are opening diameter, Capacity of system, discharge rate, hopper filling and level control devices. Screw feeder is next component after hopper. Screw feeder is used for transporting bulk material and for conveying hot or cold material. Screw feeder controls rate of material which is discharge from hopper. It is used for controlling flow rate for varying speed operation based on application. Horizontal screw feeder is used for the system. Material of screw feeder and hopper is stainless steel.Stainless steel has properties like corrosion resistance, higher ductility and higher strength; hence it is used for food industries.
\end{abstract}

Keywords: AC Motor with 1440 rpm, Hopper, Screw feeder, pulleys, Belt conveyor, PLC Circuit, Metal Detector etc. ****.

\section{INTRODUCTION}

The main purpose of material handling system is transportation and handling of large quantity of food and other raw materials. System includes hopper, screw feeder, belt conveyor, motor, worm and worm gear box and it is controlled by Programming language control (PLC) circuit. Hopper is the container for loose material such as grains sugar crystal etc. and it is tapered in design. Shape of the hopper is conical .Screw feeder is mounted on shaft. Screw rotating in a trough of $95 \%$ and it gives translation motion to the material. The principal is similar to screw sliding into nut. In this system polymer belt has been used for transportation which is mounted on trough idlers. Material handling involves movement of material in manufacturingsection. It includes loading, unloading, from source to destination. It includes carrying idler, return idler, pulleys, gear box and motor. In this system we have to use worm and worm gearbox for the screw feeder, motor to drive the belt as well as transfer the motion. The design of a belt conveyor system involves calculations of hopper capacity, screw feeder arrangement in the system.

Main Equipment's used for designing

1. Hopper

2. Screw Feeder

3. Belt Conveyor

\section{PLC circuit}

Design parameters

1. Hopper

I. Capacity of hopper in tons

II. Opening diameter

III. Determine experimentally the wall friction angle

IV. Calculation of length

V. Calculation of area

VI. Calculation of volume

2. Screw feeder

I. Feeder capacity

II. Material code

III. Selection of motor

IV. Calculation of horsepower

V. Determine size of various components

3. Belt conveyor

I. Determination of thickness of belt conveyor

II. Determination of motor power

III. Belt selection

IV. Selection of carrying and return idler with its spacing

V. Selection of snub pulley

VI. Calculation of forces on belt

VII. Calculation of tension 


\subsection{Information required to Design Belt Conveyor}

1. Centre to centre distance between pulleys

2. Maximum capacity convey per hour

3. How material is to be feed to the belt and particulars of feed point or points

4. Quantity of material is to be discharge from the screw feeder

5. Power available for driving the motor

\subsection{Objectives}

1. To convey crystalline bulk material.

2. Design of screw feeder to transport constant load with variable speed.

3. Automation by applying Programmable Logical Controller.

4. Measuring discharge on belt conveyor using weighing sensor (check weigher).

5. Finding tensions on belt and pulleys at various points.

6 . Finding failure points in the whole system

\section{WORKING OF SYSTEM}

Hopper is used as a container for raw sugar. Hopper has discharge at its bottom. Raw sugar flows in downward direction due to gravitational force.. In this material handling system horizontal screw feeder is used. They are used in many food industries. Screw feeder consists of shaft and rotating helical blade which gives forward motion to material. Screw feeder is used for controlling variable speed according to output of the system. The rate of volume of material discharge is directly proportional to rotational speed of the shaft. It is also used in inclined belt conveyor system. In inclined belt angle of inclination increases with decreasing output or flow rate. Similarly it is used to distribute, feed and mixes the material. At the end of screw feeder belt is placed. Therefore, from screw feeder sugar falls on belt conveyor. Belt conveyor is important and main component regarding to the system. Belt conveyor consist of pulleys, return and carrying idlers, rollers, motor, snub pulley, polymer belt (having 3 plies), screw take up. Conveyor system is used to transmit material over fixed path which may be horizontal or inclined direction. Conveyor belt uses pulley and is supported by rollers along its path. It consists two pulleys on which conveyor belt rotates. Motor is connected to the drive pulley. When power is transmitted to the drive pulley then pulley starts rotating and belt moves forward. Belt transmits unit as well as bulk load. Belts consist of one or more layers of composite material. It provides linear strength and to sustain all forces acting on belt is called carcass. Carcass having different types. Generally polymer is used as belt material. With the help of PLC controller it is more reliable and efficient to control. Idlers are provided for support and it gives low resistance to movement of belt. Assembly of idlers and rollers gives proper shape to belt conveyors. Troughing rolls provides axial load due to inclination of belt.

\subsection{Cad Modeling}

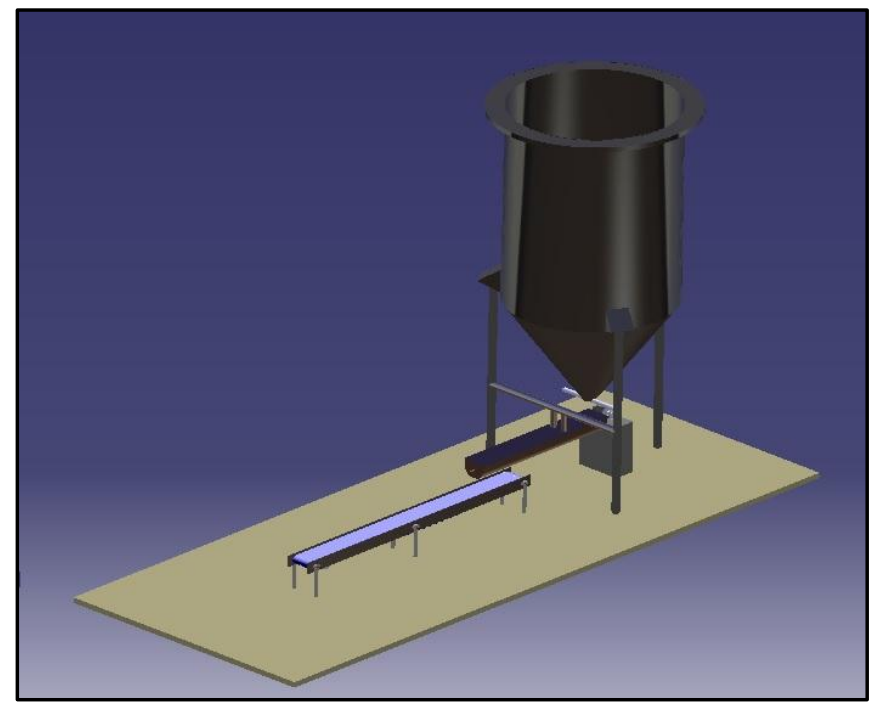

Fig-1: Cad modeling (Catia)

\subsection{Belt Conveyor Detail View}

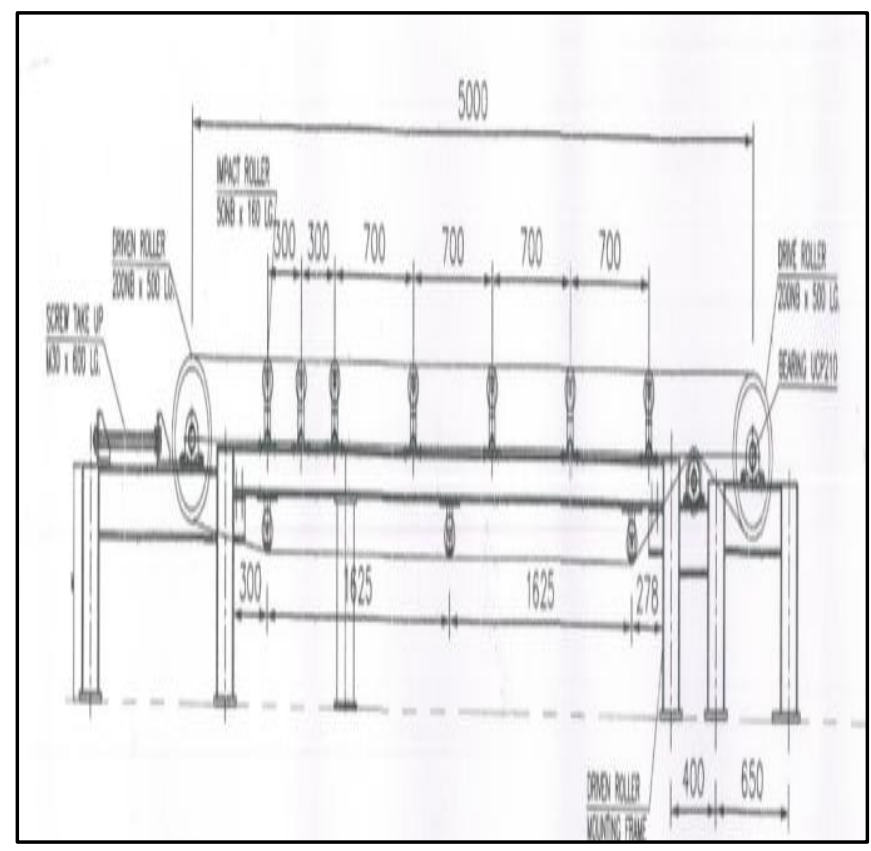

Fig-2: Detail view of Conveyor Belt

\section{ELECTRONIC COMPONENTS USED IN}

\section{SYSTEM}

1. Metal detector

2. Check weigher

3. PLC controller

\subsection{Metal Detector}

Metal detector is an electronic component which detects ferrous or non-ferrous material on belt. Metal detector is mounted on belt conveyor usually at mid or at the end. Metal particles present in food material spoils the food also it is hazardous for human health. It also decreases quality of the food. Hence, the need of system is to remove foreign 
partials like metals. At the time of production many system operation involves use of metal material like cutting, mixing, packing, crushing, slicing etc. because of this risk of metal contamination present in sugar increases and it is very challenging and important factor to remove foreign particles from sugar. Metal detectors are classified as balanced coil system and unbalanced coil system. Mostly in food industry balanced coil system is used.

\subsubsection{Working of Metal Detector}

If any metal particle present in the raw sugar comes in contact with the magnetic coil, it is cut and the potential difference occurs, thus sending a signal to the PLC circuit and the metal is detected.

\subsection{Check Weigher}

Check weigher is automatic or manual control machine, which is used for weighing packed products; it is placed at the end of the system to check weight at the output. It is usually used in mass production that is check weigher is a system that weighs items as they pass through production line. In a given system hopper capacity feeder, discharge and conveyor output is control by PLC controller.

\subsubsection{Uses of Check Weigher}

1. Check for under or over weight of packets.

2. Classify product according to their weight grades.

3. Checking of weight after and before process.

4. Checking of overall efficiency.

5. Avoid product quality problem.

\subsubsection{Selection Criteria for Check Weigher}

1. Maximum weight of the sugar

2. Velocity of the belt

3. Quantity of sugar.

4. Temperature of the system

\section{PLC CONTROLLER}

Programmable logic controller (PLC) plays important role in system. PLC is used for industry to increase the production rate. PLC is micro controller which is based on input and output require for the system. It is more reliable and efficient. PLC also increases flexibility of the system. It gives faster response hence, error in the system reduces. According to user created logic is stored in the memory.

\subsection{Ladder Diagram}

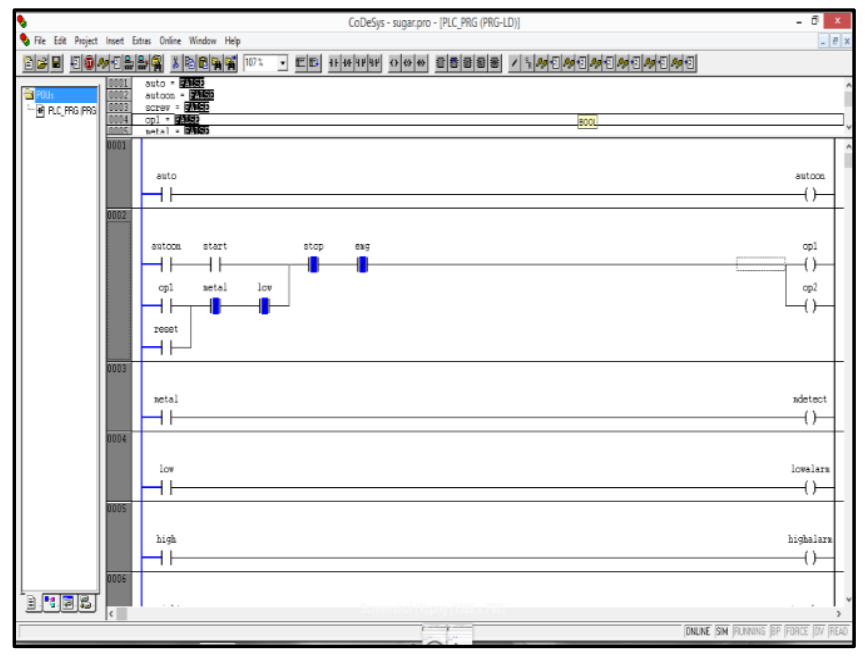

Fig 3: Ladder Diagram of PLC

Basic components used in PLC system

1. Processor/ controller

2. Input output model

3. Power supply

4. Programming software

5. Network interference

1. Processor or controller

Processor is the brain of PLC. Processor runs the feeded program. PLC programmer reads the status of input device. For example starting of the motor, speed variation etc.

2. Input output module

Input devices converts' electrical signal to the programmable language. Output devices converts programming language to electrical signal.

Examples: Input module-switches

Output module-alarm

3. Power supply

Power supply is needed to provide power for PLC. Input cable is connected to power supply.

\section{Programming software}

System includes two level sensors. That is high level sensor and low level sensor. High level sensor is placed at 45ton capacity. Low level sensor is placed at 20ton. In PLC programming, starting of motor operation is displayed on monitor screen. If any metal is detected in the sugar then system will stop. After the metal is removed by manual inspection the metal is again restarted. At the end of belt conveyor check weigher is placed which is used for measuring discharge capacity of 20ton/hr. This signal is also connected to PLC circuit. If any emergency happen the system will stop and damage is avoided.

Advantages:

1. It is suitable for food and chemical industry.

2. Easy to operate.

3. User friendly.

4. Fast working. 


\section{NUMERICAL RESULTS OF SYSTEM}

\subsection{Analysis of Hopper}

\subsubsection{Total Deformation of Hopper}

Total maximum deformation in hopper is 0.011872 .

Maximum deformation occurs at the opening of the hopper.

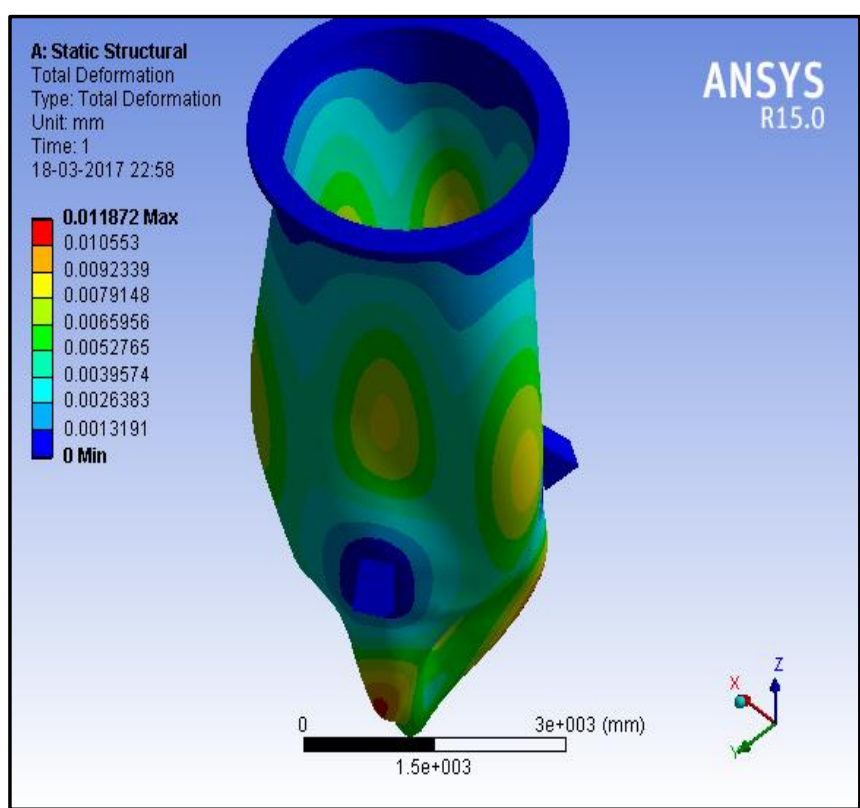

Fig 4: Total Deformation of Hopper

\subsubsection{Stress Developed on Hopper}

Maximum stress developed on hopper is $1.312 \mathrm{MPa}$.

Stress developed IS minimum at the fixed side of the hopper

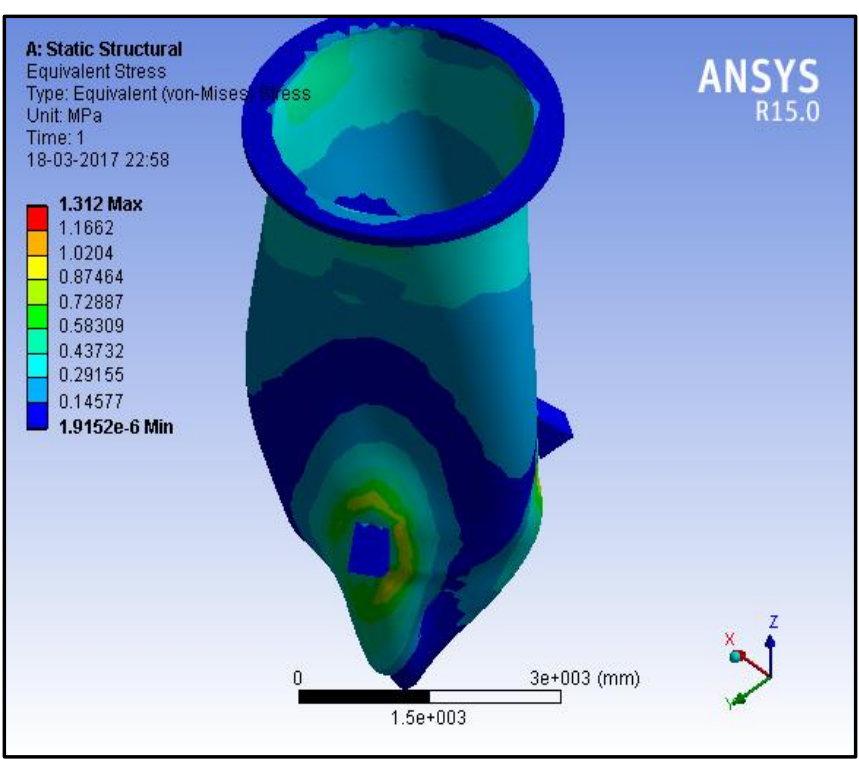

Fig 5: Stress Developed on Hopper

\subsubsection{Equivalent Elastic Strain on Hopper}

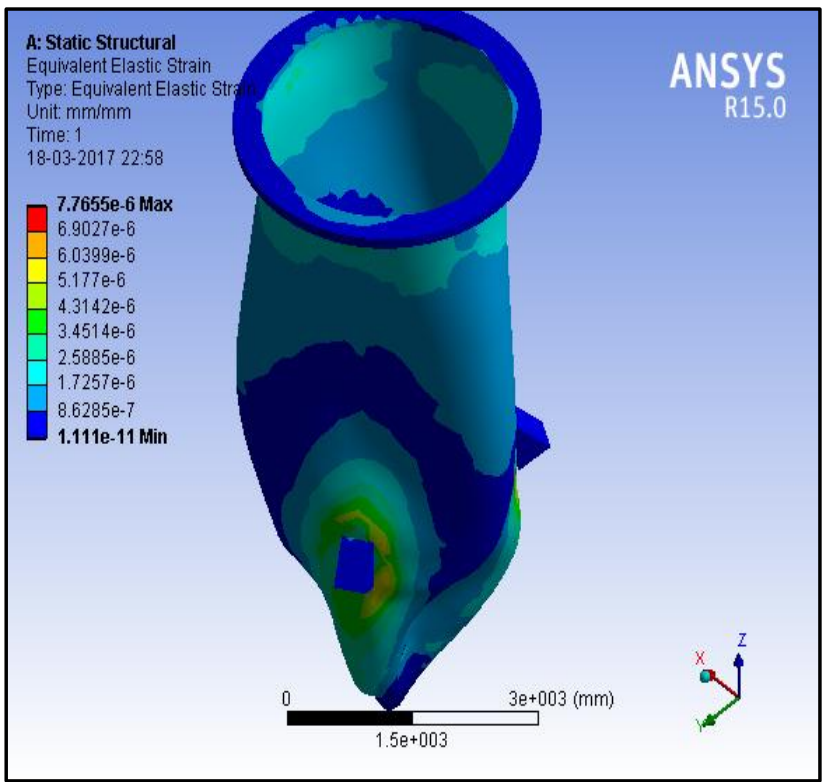

Fig 6: Equivalent Elastic Strain on Hopper

\section{ANALYSIS RESULT OF SCREW FEEDER}

\subsection{Total Deformation of Screw Feeder}

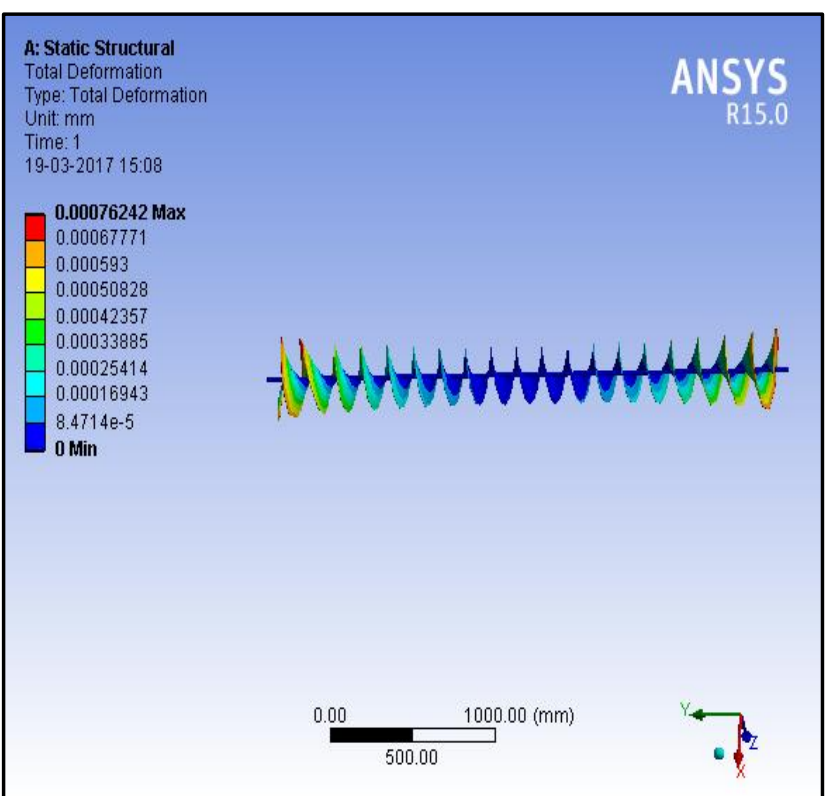

Fig 7: Total Deformation of Screw Feeder 


\subsection{Stress Developed on Screw Feeder}

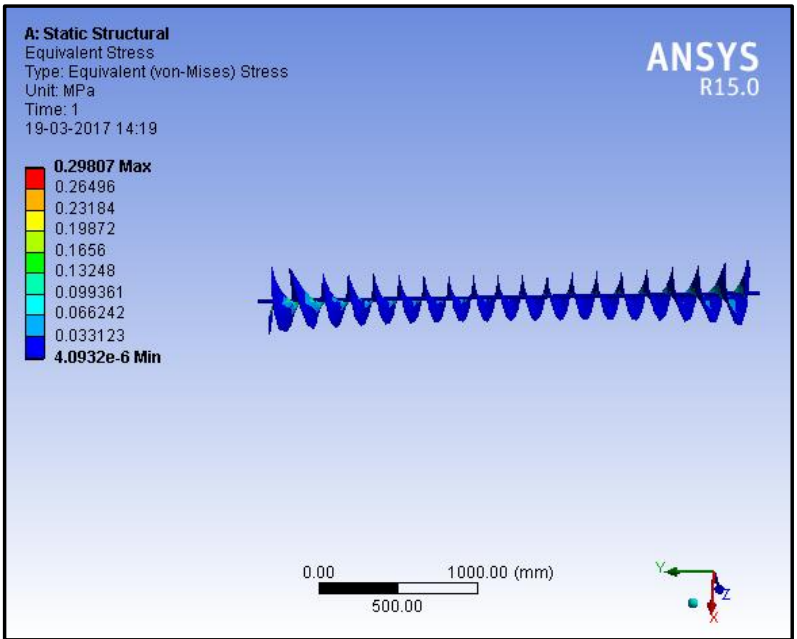

Fig 8: Stress Developed on Screw Feeder

\subsection{Equivalent Elastic Strain on Screw feeder}

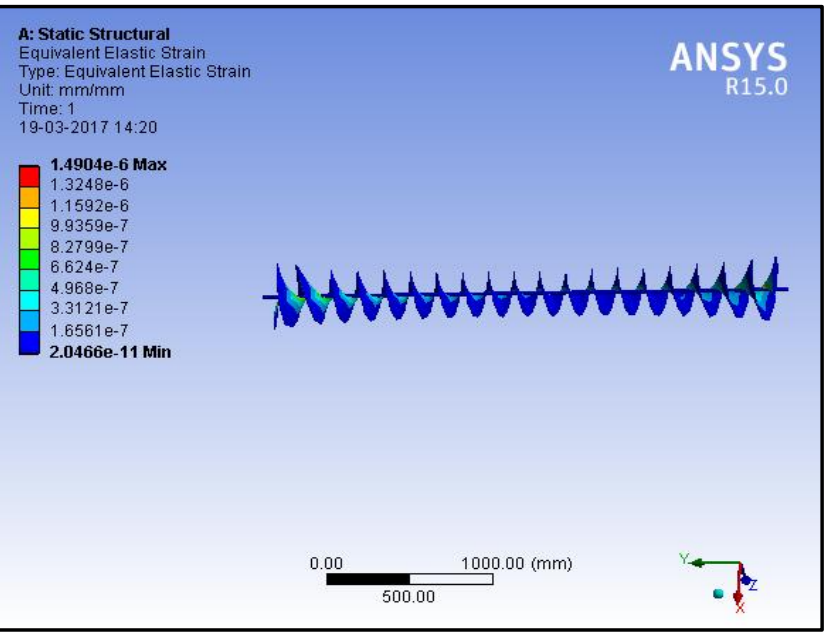

Fig 9: Equivalent Elastic Strain on Screw feeder

\section{ANALYSIS RESULT OF BELT CONVEYOR}

\subsection{Total Deformation of Belt Conveyor}

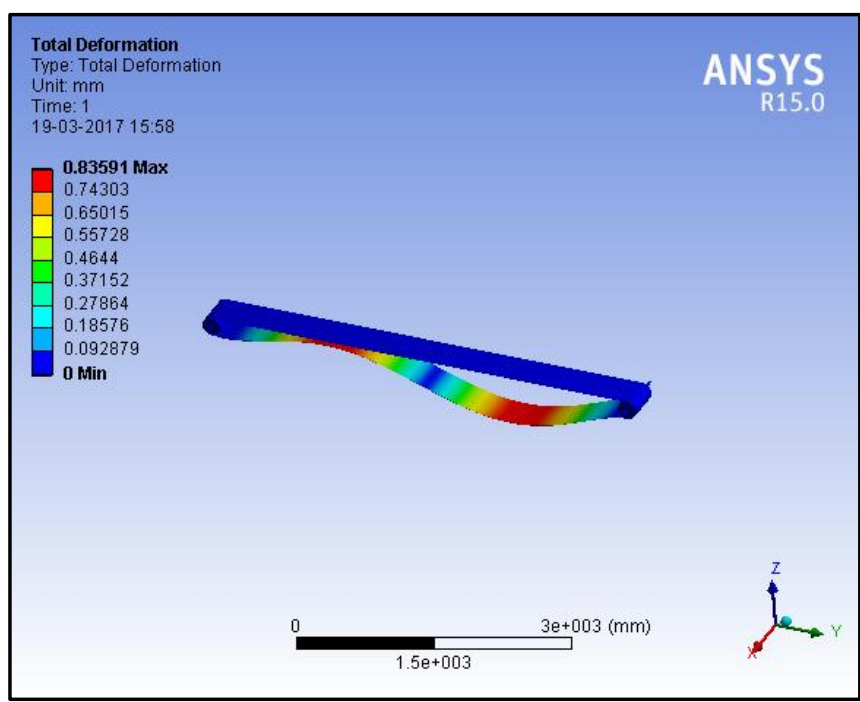

Fig 10: Total Deformation of Belt Conveyor

\subsection{Stress Developed on Belt Conveyor}

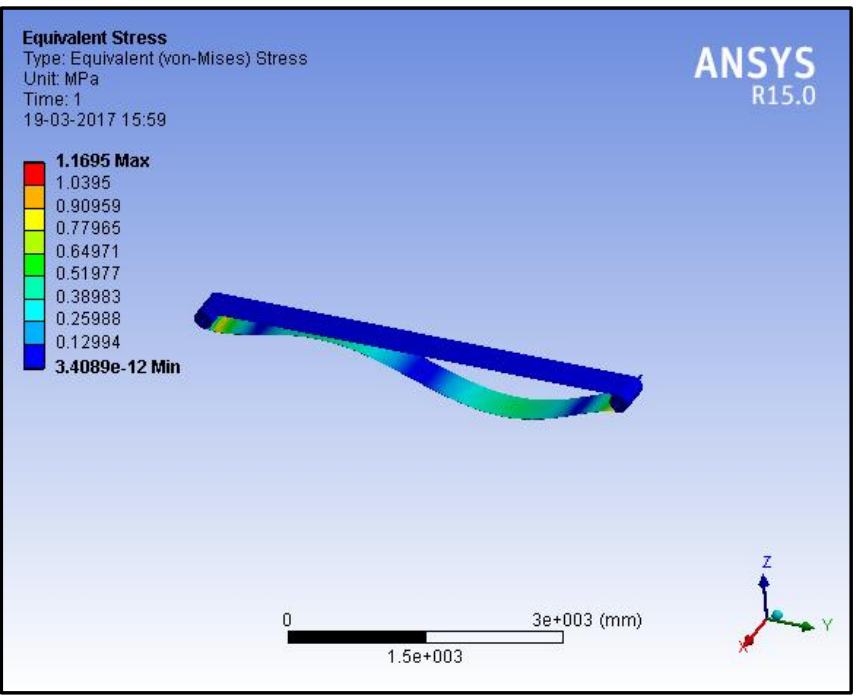

Fig 11: Total Deformation of Belt Conveyor

\subsection{Equivalent Elastic Strain on Belt Conveyor}

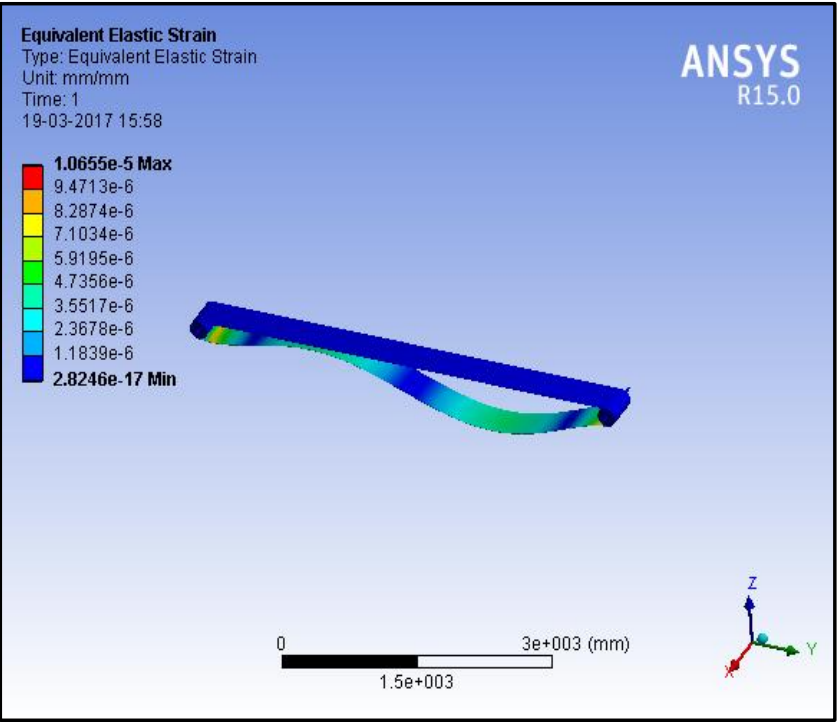

Fig 12: Equivalent Elastic Strain on Belt Conveyor

\section{CONCLUSION}

This project provides detail knowledge and study about design of material handling system. Project gives brief idea on selection of conveyor belt for conveying or transformation of the crystalline material like sugar, salt etc. The major parameters like belt capacity, belt width, belt tension, screw feeder, motor, gear box, idlers diameter of shaft, pulleys etc. were successfully designed using the standards and research papers. By using gear motor and gear box the jerk can be reduced by reducing speeds. The maximum speed reduction carried out was 1440/45.47. That is 31.66. It is also very flexible, safe with low initial, maintenance and operational cost. We have used PLC program for the actuation of conveyor system. We faced some problems during programming and later changes were made and the program was successfully done. 


\section{REFERENCES}

[1] A.M. GUTHRIE and J.R. PILCHER "Design of belt conveyor for bulk sugar handling" April 1968

[2] KONKALLA NAGA SRI ANANTH and VAITLA RAKESH "Design and selecting the proper conveyor belt” (IJAET) E-ISSN 0976-3945.

[3] CHITRA.S and VIJAYA RAGHAVAN "Conveyor control using programmable logic controller" (IJAERT) Volume 3, Issue 8, August-2014 ISSN 2278-7763.

[4] Ganesh B. Shinde, Vishal .P. Ghadge , Akshay .A.Ghadve, Dr. D.K. Shedge " PLC based auto weighing control system" (IJETR) Volume 3, Issue 03, ISSN 2321-0869, March 2015. 